\title{
Information Therapy: Bridging the information gap between doctors and patients
}

\author{
Raj Sonikal, Vijay Lakshmi Sharma ${ }^{2}$, Amarjeet Singh ${ }^{3}$
}

${ }^{1}$ Research Scholar (Public Health); ${ }^{2}$ Professor and Coordinator,; Centre for Public Health, Panjab University, Chandigarh. ${ }^{3}$ Professor, School of Public Health, Post Graduate Institute of Medical Education and Research (PGIMER), Chandigarh, India.

\begin{abstract}
Lack of understanding of medical terms and healthcare information by patients can lead to adverse health outcomes and decreased satisfaction with the clinician and medical encounter. Moreover, due to advent of information technology, lot of health and medical information is available on World Wide Web. However, the information available is not reliable and trustworthy and cause serious consequences. Therefore, the right information should reach right person at the right time in order to support the patient in making health-related decisions. 'Information therapy' (Ix) is an attempt to provide patients with the timely, adequate and evidence-based health information for making informed decision regarding their treatment. The information provided should be relevant, accurate, complete, reliable, easy to understand and practical. Ix is exactly like treatment prescription by a physician but it also includes reference to healthcare information resources to patients following a clinical visit. The patients or the care takers after going through these resources can understand their medical condition and may raise patient satisfaction, leads to better health outcomes and reduce medical errors. Ix is a cost-effective solution that allows the healthcare industry to patient-centered care. It also allows patients to serve themselves, and save doctor's precious time, which ultimately helps to utilize limited resources in an efficient way, especially in developing countries. Ix is a need of the hour in today's world, however, scope is limited by the challenges like inadequate literacy level of population, poor IT access to majority rural population, limited resources to develop right information and lack of information specialists and medical librarians in developing countries.
\end{abstract}

Keywords: Information therapy, Information technology, Patient-centered care, Decision-making, Health outcome.

\section{Introduction}

The communication of patients and health professionals is one of the essential component for the delivery of high quality healthcare. Lack of understanding of medical terms and healthcare nformation by patients can lead to decreased adherence to treatment recommendations, adverse health outcomes, decreased satisfaction with the clinician and medical encounter. ${ }^{1}$ During the brief periods of hospital admission and discharge, patients often receive a large amount of important information. This information is often not standardized ${ }^{2}$ and patient tends to forget $40 \%$ $80 \%$ of information they receive. ${ }^{3}$ Most of the adverse events during hospital stay and post-discharge could be prevented or reduced by better and effective communication among patients and doctors. ${ }^{4}$ The adequate and correct information furnished by healthcare provider improves patients' health literacy and in turn assist in informed decision making about their treatment and care. ${ }^{5}$ Most importantly, patients have the right to access the accurate and clear information about their illnesses. $^{6}$

\section{Definition of Ix}

The right information should reach the right person at the right time in order to support the patient in making healthrelated decisions. ${ }^{7}$ 'Information therapy' (Ix) is a broader term which combines the aspects of providing relevant

\section{Practice Points}

- In order to make informed decision making, patients should have access to right information at right time.

- Information therapy (Ix) is the prescription of relevant and accurate information to patient according to their needs and preferences.

- The provision of Ix would lead to better health outcomes, patient satisfaction, reduces the cost of care and medical errors.

- Ix is a cost-effective solution and can help to utilize limited resources in an efficient way, especially in developing countries.

- Scope is limited by the challenges like inadequate literacy level of population, poor IT access to majority rural population, limited resources to develop right information and lack of information specialists and medical librarians in developing countries.

information with patient needs and preferences. $^{8}$ According to Andersen, Ix is 'the prescription of information intended to help patients understand their

Correspondence: Dr. Sonika Raj, Research Scholar (Public Health), Centre for Public Health, Panjab University, Chandigarh, India. Email: sonikagoel007@yahoo.com. 
health and their health care issues" ${ }^{\prime}$. Ix pledges an active and informed participation of patient in the healthcare process. ${ }^{10}$ So, Ix is an attempt to provide patients with the timely, adequate and evidence-based health information for making informed decision regarding their treatment. Embedding Ix within every medical encounter can also help patients to assume a more active and involved role in their healthcare. ${ }^{11}$

The right information is the one which is relevant, accurate, complete, reliable, easy to understand and practical. The right information is tailored according to right person i.e. patient's need based on his demographics like from urban or rural, level of literacy, learning style like preference for online or print or multimedia sources of health information, stage of behavior change, health beliefs and co-morbidity. ${ }^{12}$ The information should be provided to the patient at the right time, i.e. targeted to the appropriate moment in care whether prevention, screening, pre-diagnosis, diagnosis, acute care, decision making, chronic care or end-of-life care. ${ }^{12}$

\section{Types of IX}

The Ix can be physician directed or non-physician directed. ${ }^{8}$ The physician directed Ix is exactly like treatment prescription by a physician but it also includes reference to healthcare information resources to patients, therefore also known as Information prescription. In non-physician Ix, the patients or caretakers search for health information through various sources. Usually the information they may find is generalized and suitable for general masses rather than individualized which may not necessarily supports the treatment decision. ${ }^{8}$ It is very much similar to Over The Counter (OTC) medications in which people buy medicines following a self diagnosis. ${ }^{13}$ This specificity factor differentiates Ix from other kind of general health information. Literature has shown that personalized information is more relevant, credible and effective in influencing health behavior than general health messages. ${ }^{14}$ Thus, information prescription is a novel approach that offers more standards to ensure the quality of information and healthcare. ${ }^{13}$

There has been ignorance about the use of information therapy globally. A systematic review done by Gavgani \& Shokraneh ${ }^{8}$ found that most of the related studies belong to developed countries. It showed that there was improvement in knowledge and satisfaction of patients on receiving Ix. Fulfillment of Ix relies on mainly three factors i.e. patients preference, physicians interest and information technology (IT). A study conducted in Iran showed that all patients demanded Ix service offered by the physician. ${ }^{15}$ Even qualitative study done in developed country found that the physicians believed that most patients were not interested in acquiring additional information and that the patients rely on their doctor. ${ }^{16}$ So, there is a need of changing the physicians' attitude to refer patients to information resources. There is a very little evidence regarding the usage of information therapy in developing world. Moreover, literature is primarily available on satisfaction of physicians, patients and librarians with Ix services but very few studies demonstrates improved health outcomes due to prescription of information.

\section{Ix and Information Technology (IT)}

Due to the advent of IT, an unprecedented amount of health information is now within reach of healthcare consumers. ${ }^{17}$ Patients and their caregivers have now $24 / 7$ access to millions of health related articles and news on a click of button. The advent of smart phones has taken this information availability to the next level. Such general information can help in empowering the individual in making health related decisions. But if the information found is incomplete, inaccurate and misleading it can be more dangerous than useful. ${ }^{18}$ This information overload has resulted in information smog, confusion and uncertainty. A systematic review found that $90 \%$ of the web sites provide incomplete and unreliable information. ${ }^{19}$ Bader et $a l^{20}$ has also concluded that availability and accessibility of large amount of information does not ensure best health decisions and outcomes. Even despite wider availability of information, the communication between a physician and patient is lacking and messages are often misunderstood. ${ }^{21}$ The concept of Ix bridges this information gap by involving patients' in their healthcare decisions and participation in their own well-being, and thus decrease the utilization of healthcare resources.

\section{Importance of IX}

Ix applications can provide the appropriate preparation so that the limited time in the physician's clinic is optimized for both patient and clinician. ${ }^{22}$ The doctors can utilize the available interaction time to discuss specific questions with well informed patients rather than answering the general questions. Hence, Ix is a tool for pre-activation, enhances the level of dialogue between two parties so that they would be able to discuss specific actionable steps and thus will allow for effective management of chronic conditions. ${ }^{23}$ Physician can then prescribe information to patients by referring them to specific websites or booklets or modules etc. that have already been evaluated and confirmed by experts and has relevant, reliable, evidence based, upto-date, information. ${ }^{7}$ The provision of such accurate information may raise patient satisfaction, leads to better health outcomes, reduce the cost of care and medical errors. ${ }^{24}$ It would reduce patient anxiety and improve compliance and adherence to medications. It would also enable them to make better decisions regarding family, promote self care and also provide them with evidence based guidelines so that they can ask for right medical treatment. Ix also reduces the cost by preventing unnecessary surgeries, investigations and clinical visits. $^{22}$ Ix would help to promote and encourage preventive measures for health and thereby decrease the risk for acute needs. Cost savings within health care delivery become especially important in developing countries, wherein majority of health expenditure is out of pocket. ${ }^{25}$

The delivery of Ix by physicians appears to be time consuming at first instance, but as on whole, it saves the

South East Asia Journal of Public Health 2014;4(2):47-50 
time of physicians in subsequent visits. The patients or the care takers after going through these resources can understand their medical condition in a better way and thus will increase the compliance to the treatment. This is quite important in chronic diseases where the patients and their caretakers are in contact with their physicians for a longer period of time. Patient will be more satisfied with the treatment and would help to build their reputation.

\section{Format to deliver Ix}

The format to deliver Ix should depend on patients' preferences.$^{22}$ It can be through print media (books, leaflets, pamphlets) or digital media or by both. Patients can also be given after visit summary so that they can remember the information told during the medical encounter. Patients with poor or marginal literacy can be provided with health information through multimedia formats like audios, videos, films or animations for better understanding. ${ }^{26}$ However, web-based information prescriptions have many advantages as the information can be updated very quickly and easily. It can be accessible to all the patients with internet facility and can be translated into different languages easily. Moreover, patients' can use the information at their own pace and time. Once uploaded on the website, there are no recurrent costs for the doctor and the hospital. ${ }^{22}$

\section{Implications for healthcare industry}

Thus, Ix is a cost-effective solution that allows the healthcare industry to shift to patient-centered care. ${ }^{27}$ It also allows patients to serve themselves, and save doctor's precious time, which ultimately helps to utilize limited resources in an efficient way, especially in developing countries. $^{22}$ It helps to overcome the situation where there is a shortage of healthcare providers. Further, the optimal availability and expansion of IT shall serve an icing on the cake. ${ }^{28}$ However, its scope is limited by the challenges like inadequate literacy level of population, poor IT access to majority rural population, limited resources to develop right information and lack of information specialists and medical librarians in developing countries. $^{29}$

\section{Conclusion}

Ix is a need of the hour in today's world, where a lot of health and medical information is available on World Wide Web. However, the information available is not reliable and trustworthy and can cause serious consequences. Thus, Ix can play the major role in improving patients' safety. It is recommended that policy makers should focus on providing easy to use inexpensive IT tools to doctors and recruiting information specialists and medical librarians in the hospitals so that they can prescribe preventive and therapeutic information to patients tailored according to their needs. IT companies should work to create easy to use, reliable, uncomplicated and evidence based health information databases. There is a need to create awareness in order to generate a growing consumer demand for Ix. Further, there should be a continuing focus on teamwork in the hospital which not only consists of doctors, nurses, pharmacists but also information specialists. In the future, research focused on direct health outcomes of Ix is needed as well. Last but not the least, Ix and IT should work in a synergistic way to create a trustworthy and cost-effective healthcare system.

\section{References}

1. Kemp EC. Patients Prefer the Method of 'Tell Back- collaborative Inquiry' to Assess Understanding of medical Information. $J \mathrm{Am}$ Board Fam Med 2008;21(1):24-30.

2. Coleman EA, Berenson RA. Lost in transition: challenges and opportunities for improving the quality of transitional care. Ann Intern Med 2004; 141(7):533-6.

3. Kessels RP. Patients' memory for medical infor mation. J R Soc Med 2003:219-22.

4. Bartlett G, Blais R, Tamblyn R, Clermont RJ, Mac Gibbon B. Impact of patient communication problems on the risk of preventable adverse events in acute care settings. CMAJ 2008; 178 (12):1555-62.

5. Coulter A, Parsons S, Askham J. Where are the patients in decision-making about their own care? Copenhagen: WHO, 2008.

6. Pang $\mathrm{T}$ et al. A 15th grand challenge for global public health. Lancet 2006;367:284-6.

7. Kemper DW, Metler M. Information Therapy: prescribed information as a reimbursable medical service. Boise, Idaho: Healthwise, 2002.

8. Gavgani VZ, Shokraneh F. Information Therapy (Ix), Information $\mathrm{Rx}$ and Information Prescription: a systematic review. Int $J$ UserDriven Healthcare 2013; 3(2):9-19.

9. Andersen CM. Information therapy: a prescription for the digital era. Health Care Manage 2013; 32(3):242-245.

10. Gavgani VZ. Evidence Based Information Prescription (IPs) in Developing Countries, Evidence Based Medicine - Closer to Patients or Scientists? 2012. In: Nikolaos Sitaras (Ed). Evidence Based Medicine - Closer to Patients or Scientists? Rijeka, Croatia: InTech, 2012.

11. Gavgani VZ. Information Therapy (Ix) and patients' preference. Int $J$ Comput Models Algorithms Med 2011; 2(2):42-50.

12. Throop Cindy, Seidman J. Ix for treatment adherence. Report. Washington, D.C.: Center for Information Therapy, 2009.

13. NHS. Information Prescription Service - NHS Choices. http://www.nhs.uk/ipg/pages/ aboutthisservice.aspx (accessed February 2014)

14. Skinner CS, Campbell MK, Rimer BK, S. Curry $\mathrm{S}$, Prochaska JO. How Effective is Tailored Print Communication. Ann Behav Med 1999;21:290-8. 
15. Gavgani VZ, Biswas R. Information Therapy for patient centered Healthcare: Evidence Based Frameworks.Hershey, PA: IGI Global, 2013.

16. Leisey MR, Shipman JP. Information prescriptions: a barrier to fulfillment. JAMA 2007;95:435-8.

17. Bradford W. Hesse BW, Nelson DE, Kreps GL, Croyle RT, Arora NK, et al. Trust and Sources of Health Information. The Impact of the Internet and Its Implications for Health Care Providers: Findings from the First Health Information National Trends Survey. Arch Intern Med 2005; 165(22):2618-24.

18. Bhandari S, Kapoor A. Catching the ehealthcare bug, Webchutney Digital healthcare report, 2011. www.slideshare.net/sidharthrao/ webchutney-digital-healthcare-report-2011 (accessed November 2014)

19. Eysenbach G, Powell J, Kuss O, Sa ER. Empirical Studies Assessing the Quality of Health Information for Consumers on the World Wide Web: A Systematic Review. JAMA 2002; 287(20):2691-2700.

20. Bader SA, Braude RM. Patient informatics: creating new partnerships in medical decision making. Acad Med 1998; 73:408-11.

21. Wagner TH, Hibbard JH, Greenlick MR, Kunk el L. Does providing consumer health information affect self-reported medical utilization? Evidence from the Healthwise Communities Project. Med Care 2001; 39:83647.

22. Malpani A. Using information therapy to Put Patients First. Colorado Springs: CreateSpace
Independent Publishing Platform, 2012.

23. Seidman J, O'Kane ME. Turning on the Light: Illuminating the Care Experience Through a New Consumer Paradigm for Quality Measurement. Washington, D.C.: Center for Information Therapy, 2004.

24. Beisecker A, Beisecker T. Patient InformationSeeking Behavior When Communicating with Doctors. Med Care 1990; 28(1):19-28.

25. Gwinn BR, Seidman J. The Ix Evidence Base: Using Information Therapy to Cross the Quality Chasm. Washington, D.C.: Center for Information Therapy, 2004.

26. Jeste DV, Dunn LB,_Folsom DP, Zisook D. Multimedia educational aids for improving consumer knowledge about illness management and treatment decisions: A review of randomized controlled trials. J Psych Res 2008; 42(1):1-21

27. Adams S, Bont A. Information Rx: Prescribing Good Consumerism and Responsible Citizenship. Health Care Anal 2007;15:273-90.

28. Mokhtar IA, Majid S, Foo S. Using information technology to improve health information literacy in Singapore - An exploratory study.2006. Proc. ITI 4th International Conference on Information and Communications Technology (ICICT), Cairo, Egypt, December, 10-12, 60-71.

29. Johansen SG. Software development with limited resources in a developing country: A study of the effects of limited resources on the development of a person-based family healthsystem in India. [thesis]. Trondheim: Norwegian University of Science and Technology, 2007. 